\title{
Normal Axis Deviation by ECG Finding
}

National Cancer Institute

\section{Source}

National Cancer Institute. Normal Axis Deviation by ECG Finding. NCI Thesaurus. Code C41355.

An electrocardiographic finding about the position of the heart in the chest (axis). The electrical axis of the heart is a term used to describe the mean direction and magnitude of electrical impulses generated by the heart during the cardiac cycle. Normally, the heart is positioned in the chest so that the majority of the electrical impulse travels downward (interior) and towards the left. The normal axis of the heart is called normal axis deviation. Age, body build, and sex may influence axis location and produce a number of normal variations. The axis may deviate from normal position due to structural problems (valve conditions), pulmonary or systemic hypertension and/or heart attacks. 